\title{
Constituição de redes de convivência com portadores de sofrimento psíquico através de recursos informatizados ${ }^{*}$
}

\section{Deise Juliana Francisco** \\ Cleci Maraschin}

\begin{abstract}
Resumo: A atenção à saúde mental no Brasil está transversalizada por ações de desinstitucionalização e de criação de espaços sociais. O projeto de extensão "Criando laços via recursos informatizados", realizado numa universidade comunitária do interior do RS em parceria com o CAPS local objetiva atuar na constituição de redes de convivência e no agenciamento criativo de portadores de sofrimento psíquico. Trata-se de pesquisa qualitativa, com diário de campo e análise das produções do grupo (uso de aplicativos, e-mail, fóruns, sites etc.). Como resultados aponta-se que os portadores de sofrimento psíquico têm-se engajado nos ambientes virtuais, demonstrando interesse em aprender e produzir. $\mathrm{O}$ trabalho com imagem pessoal e autobiografia teve efeitos na subjetividade e ressoou positivamente no ambiente familiar.
\end{abstract}

Palavras-chave: sofrimento psíquico - pesquisa intervenção - informática na educação

Constitution of nets with carriers of psychic suffering through informatizados resources

Abstract: The attention to the mental health in Brazil is acrossed by action of creation of social spaces. The extension project "Creating bows saw informatizados resources", carried through in a communitarian university of the RS in partnership with the local CAPS to act in the constitution of nets and in the creative agency of carriers of psychic suffering. One is about qualitative research, with daily of field and analysis of the productions of the group (use of applicatory, email, fóruns, sites etc.). As results are pointed that the carriers of psychic suffering have engaged themselves in virtual environments, demonstrating interest in learning and producing. The work with personal image and autobiografia had effect in the subjectivity and resounded positively in the familiar environment.

Keywords: psychic suffering - research intervention - computer science in the education

\section{Introdução}

O artigo refere-se à intervenção realizada em nível de projeto de extensão em uma universidade do interior do estado do Rio Grande do Sul intitulado "Criando laços via recursos informatizados". Trata-se de uma parceria entre a Universidade Regional Integrada do Alto Uruguai e das Missões - URI Campus Santo Ângelo, o CAPS de Santo Ângelo, envolvendo o Grupo de Pesquisa e Desenvolvimento da EAD (GPEAD/URI) e o Laboratório de Estudos de Linguagem Interação e Cognição (LELIC/UFRGS). Os trabalhos iniciaram-se em junho de 2004.

O objetivo do projeto é constituir redes de convivência digitais a partir do dispositivo de criação de espaços de vivência subjetiva com o uso de recursos 
informatizados em equipe junto a portadores de sofrimento psíquico, usuários do CAPS.

A intervenção vem sendo agenciada por uma equipe extensionista - formada pela coordenadora, duas alunas voluntárias, duas bolsistas de extensão, todas do curso de Psicologia e um bolsista do curso de Computação - e por 07 usuários por dia, num laboratório com 07 computadores ligados em rede. Os encontros ocorrem duas vezes por semana, sendo que cada usuário participa de um dia apenas por semana.

Está constituída enquanto pesquisa-intervenção, na qual a produção de conhecimento e a construção do objeto de pesquisa ocorrem no momento mesmo da imbricação do pesquisador (ou equipe de pesquisadores) na ação prática, rompendo-se, assim, os limites que a ciência moderna constituiu entre pesquisador e objeto do conhecimento (Cecília Coimbra, 2002). Nesta proposta de pesquisa, o pesquisador está implicado no seu fazer, perpassado e transversalizado por diversas instituições. Sendo assim, uma das ferramentas da intervenção é a análise da implicação - dos lugares que o pesquisador é convocado a ocupar, os que ele deseja ocupar e o jogo de forças que se atualiza nas ações cotidianas.

Participam do projeto 09 homens e 05 mulheres, de classe popular na sua maioria, com escolaridades, estado civil e diagnóstico variados, muitos com passagem por hospitais psiquiátricos e consumidores de medicação. Aqui, a questão do diagnóstico não está sendo considerada, tendo em vista que seus objetivos contemplam a criação de espaços de potencialização de vida e não de fechamento em diagnósticos psiquiátricos, psicanalíticos ou psicológicos.

A metodologia de trabalho conta com uma reunião inicial, em que cada participante expõe o que quer fazer ou o que produziu no encontro anterior, comenta sobre suas produções e aprendizagens e de como está avaliando a oficina. Posteriormente, cada um ocupa uma máquina e desenvolve seu trabalho com o apoio da equipe e dos outros integrantes do grupo. São realizados trabalhos com texto, desenho, busca de temáticas na Internet, construção de home page, uso de fórum de discussão, do ForChat. A proposta é a de constituírem-se ações coletivas de produções do grupo e utilização de ambientes virtuais.

A aproximação entre portadores de sofrimento psíquico e computadores aposta na constituição de vínculos, de contatos, de aproximações, de rizomas nos quais alguma produção se construirá, da mesma forma em que serão apresentadas redes de relacionamento e de convívio diversas da do convívio comunitário territorial. Aqui, a intervenção faz elo com o dispositivo informático, tendo como pergunta: Como o dispositivo informático será operado pelos portadores de sofrimento psíquico e equipe extensionista e quais os efeitos disparados nesse encontro?

A pergunta-ação que se coloca é sobre os engendramentos das tecnologias com os agenciamentos coletivos de enunciação: Como criar Universos de referência e, para além de um simples contato com a tecnologia, compor complexos de subjetivação: indivíduo-grupo-máquina-trocas múltiplas, que oferecem à pessoa possibilidades diversificadas de recompor uma corporeidade existencial, de sair de seus impasses repetitivos e, de alguma forma, se re-singularizar (Félix Guattari, 1992, p. 17)?

\subsection{Tecnologia, subjetividade e saúde mental}

Manuel Castells (2000) aponta que a sociedade contemporânea pode ser traduzida como a geração de informação mediante a geração, armazenamento, recuperação, processamento e transmissão da informação, sendo que a informação e o conhecimento retroalimentando-se, conectando culturas.

A sociedade do conhecimento se caracteriza, portanto, por sua penetrabilidade, sua configuração topológica em forma de rede, regida por uma lógica de não- 
linearidade e estruturação, sua flexibilidade e potência para a convergência para um sistema integrado. A informação vai se arranjando não só com computadores, mas também com o corpo, tanto que Castells inclui nas tecnologias da informação $o$ conjunto convergente de tecnologias em microeletrônica, computação (software e hardware), telecomunicações/radiofusão, e optoeletrônica. (2000, p. 49), além da engenharia genética e suas aplicações, pois esta trabalha com informação de códigos de matéria viva, nanotecnologia e outros desenvolvimentos ocorridos na interface com o digital.

Gilles Deleuze (1992) pensa esta sociedade como a sociedade de controle, caracterizada pela desconstituição dos meios de confinamento demarcados territorialmente e pela constituição de um espaço aberto, no qual se misturam diversas instituições, possibilitando a vivência de que estamos sempre em família, em escola (ou em formação), em prisão em saúde (Leila Machado, 2001, p. 74) Na saúde mental, pode-se pensar que as intervenções domiciliares inserem-se na dita sociedade de controle, ao adentrar o espaço do domicílio e não mais centrar o atendimento apenas na unidade básica de saúde.

O controle agora se dá através de processos contínuos e sem pausa, nunca concluídos, baseado no escrutínio e na modulação das condutas, constituindo uma metaestabilidade a partir do constante movimento da informação. Paul Virilio (1999) afirma que a generalização da televigilância é exercida, constituindo um campo existencial vigiado, perscrutado e contínuo e que as tecnologias desempenham combinação importante, na medida em que possibilitam esta companhia. Nesta face dura, e controlada, constituem-se os movimentos mais diversos e subjetivações. As transformações tecno-científicas, ao comporem alterações nos campos do saber, poder e subjetivação, possibilitam a emergência de ramificações, de novas suavidades e perda das hierarquias e da burocracia, componentes das instituições (sejam elas totais ou não).

Neste contexto, os meios de comunicação agem como equipamentos coletivos de produção de subjetividades que interagem com muitos outros dispositivos, compondo universos de referência. A noção de produção de subjetividades coloca em xeque a subjetividade individualizada, fechada em um sujeito ou ressitua o sujeito enquanto 'terminal' de processos que implicam coletividades (humanos e não-humanos), num cruzamento de múltiplos e heterogêneos componentes.

Assim, a pergunta "quem é o louco?" é deslocada de uma suposta interioridade, sendo jogada no socius e abrindo-se para a multiplicidade e para o processo maquínico de criação e de relação com outras máquinas, inclusive as informacionais. Guattari, por exemplo, refere-se a uma "subjetividade assistida por computador", apontando para o engendramento rizomático inusitado que se pode constituir com as máquinas informacionais. Sendo assim, não faz sentido pensar em oposição entre técnica, homem e cultura nem na cisão entre homem de um lado (natureza) e máquina (tecnologia), não sendo possível tratar de um suposto impacto das tecnologias nas subjetividades. Ambas são diferentes, mas sua existência compõe efeitos, composições:

Existem agenciamentos coletivos, usos e apropriações das tecnologias por parte dos sujeitos, que, por sua vez, também vivenciam seus efeitos em seus próprios corpos e subjetividades. Os aparelhos e ferramentas exprimem as formas sociais que os produzem e lhes dão sentido, formando redes, teias de pensamento, matrizes sociais, econômicas, políticas, que permeiam o corpo social inteiro e estão inextricavelmente ligados às novas tecnologias (Paula Sibilia, 2002, p. 11).

\subsection{A rede: conectando tecnologias e reabilitação psicossocial}


Nestes tempos híbridos, estabelecimentos com estruturas verticalizadas, burocráticas, disciplinares, heterônomas co-existem com organizações autogestivas e mestiças. As nanotecnologias, tecnologias da medicina, farmacologia, compõem corpos e afetos em sintonia com políticas públicas e com os encaminhamentos sócio-técnicos, conformam redes.

Pode-se pensar também nas redes sociais como emergindo das coletividades e conformando formas de atuar junto aos processos sociais microscópicos. Conforme Julio Wong Un (2002), ao nível da rede existem fluxos bidirecionais de informações, experiências, e idéias, estabelecendo diálogos e processos de construção (criação) mútua entre os nós e todas as combinações/grupamentos possíveis (p. 91), escapando do individualismo. Isso pela própria configuração da rede: difusa, dinâmica, mutável, instável, sistema auto-organizado que possibilita espaço para o enfrentamento coletivo dos problemas. Isso pois a rede não pode ser descortinada em elementos mais simples, sua "simplicidade" é em si complexidade, ao trabalharmos com o nó e com as conexões entre nós. Aqui pode-se pensar na subjetividade como uma das conexões da rede social.

No caso da loucura, a reabilitação social é um princípio de intervenção que busca viabilizar redes de apoio a fim de que o portador de sofrimento psíquico venha a acessar os recursos constantes em sua comunidade. É um processo de negociação, de abertura de diálogo e de práticas envolvendo o usuário, a família, a comunidade, os serviços de atenção à saúde, constituindo-se em estratégias de criação e ampliação das ocasiões de troca de recursos e afetos entre os agentes sociais (Saraceno, 1999). Isso a fim de trabalhar com o que Rotelli (2001) chama da existência-sofrimento dos pacientes e a sua relação com o corpo social. Ou seja, aqui a intervenção reconhece a existência do sofrimento e o "trata" em conjunção com uma intervenção no social, a partir das diferenças. Qual seria, então, o caminho da "cura"? A transformação do doente em usuário do sistema de saúde, ao invés da cura, incitação de focos de autonomia: produzir autonomia, cidadania ativa, descontruindo a relação de tutela e o lugar de objeto que captura a possibilidade de ser sujeito (p. 81). Sendo assim, a saída é desierarquizar as relações com a equipe e constituir espaços coletivos de trabalho, inventar saúde, colocar a doença entre parênteses, criar outras formas de acolhimento e de produção do social, da subjetividade: abrir mão das interpretações da loucura segundo erro, incapacidade, inferioridade, doença mental e potencializá-la como diferença, um modo diferente de relação com o mundo (idem, p. 80).

\section{Material e Métodos}

Pesquisa qualitativa, com delineamento de estudo de caso. Estão sendo analisadas as produções de uma participante do projeto de extensão "Criando laços via recursos informatizados", em especial as produzidas em PowerPoint.

\section{Resultados e discussão}

Entendendo-se que os engendramentos sócio-técnicos propiciam formas diversas de subjetividade, de construção de mundo e de relações sociais e de aprendizagem, o uso de recursos informatizados no projeto extensionista supõe mais do que um recurso qualquer ou mesmo uma metodologia é, sim, um novo instrumento de mudança e de articulação de redes de relacionamento (extensão-comunidade-universidade), de pensares coletivos e implicados socialmente. A rede, neste sentido, não é apenas metáfora e modismo é sim uma aposta em caminhos de transformação e construção de 
cidadania e de formação profissional.

A infoinclusão objetiva a disponibilização de computadores para classe popular, para garantir acesso, produção, seleção e significação da informação, bem como construção de conhecimento por sujeitos oriundos de classe popular. No CAPS, a maior parcela de usuários é oriundo de classe popular, não dispondo de acesso a computadores nem a Internet. Para além da simples capacitação (aprender a usar o computador), a produção, seleção e significação da informação tem como objetivo a criação de outras possibilidades subjetivas aos portadores de sofrimento psíquico, bem como a divulgação de informações que eles achem pertinentes. Como exemplo disso temos a criação da home page do CAPS por parte de um usuário. Tal projeto desenvolve-se há um ano e tanto o usuário quanto outros usuários produzem os conteúdos. No site: http://geocities.yahoo.com.br/ekrindges é possível visualizar os links, bem como seu conteúdo.

Ainda como espaço de discussão há o fórum de discussão, disponível em www.urisan.tche.br/ criando/forum. No fórum as conversas giram em torno de assuntos cotidianos e do CAPS.

Os usuários produziram apresentações pessoais no PowerPoint, inserindo uma foto e escrevendo algumas de suas características ao lado. Essas produções ocorreram no início do projeto, servindo como forma de conhecer e utilizar os recursos informatizados, bem como de produzir sentidos tanto individuais quanto grupais. Isso porque as produções foram construídas e depois mostradas para os outros usuários do grupo. Foi solicitado por alguns usuários a impressão dos arquivos a fim de levá-los para casa e mostrá-los a seus familiares. Isso teve um efeito de deslocamento do lugar de incapaz ou pouco capaz dado ao usuário pelos familiares pelo de produtor, de alguém capaz. Captura dos afetos e dos relacionamentos mediados por computador, inter-grupo e pelas possibilidades de potência de vida emergidas do encontro com a rede informática.

Uma usuária que, até então, propunha-se a copiar (solicitava quaisquer textos, pois não tinha "idéia do que escrever"), fez sua apresentação, inserindo foto e alguns dados biográficos. Para colocar o título do slide, copiou o nome do mesmo: "charme". Então, sua apresentação pessoal ficou intitulada charme. Todos no grupo olham sua apresentação e apreciam, brincando com a palavra charme. Ela leva a cópia para casa.

Isso aponta que, mesmo na cópia, num momento aparente de repetição do mesmo, houve um pequeno deslocamento e a produção do outro, da singularidade. Após, imprimimos o material e ela levou para sua família ver. Ali, naquele momento, o charme passou a compor, juntamente com sua imagem e dados biográficos um contorno de si, um devir mulher que foi se insinuando através da estereotipia. Vislumbra-se aí, a relação dos corpos e das forças que, no encontro, agenciam-se em linhas de fuga. Captura dos afetos e dos relacionamentos mediados por computador, inter-grupo e pelas possibilidades de potência de vida emergidas do encontro com a rede informática.

Nesta produção, os corpos se penetraram, se misturaram, transmitindo afetos e fazendo enlaces com enunciados e regimes de enunciados em que novas formulações apareceram, um novo estilo para novos gestos. Tal movimento, híbrido de agentes coletivos (humanos-não/humanos), prenhe de estados maquínicos, possibilita a criação de outras formas de vida, mesmo fugidias.

As ferramentas informacionais, portanto, engendram-se nas sociedades, compondo misturas, agenciamentos maquínicos. São integrantes do arranjamento social, arranjando-se com a máquina social ou o arranjamento coletivo que os tomam em seu phylum. Neste contexto, os meios de comunicação agem como equipamentos coletivos de produção de subjetividades, que interagem com muitos outros dispositivos, compondo universos de referência. Pois, 
"Do mesmo modo que as máquinas sociais que podem ser classificadas na rubrica geral de Equipamentos Coletivos, as máquinas tecnológicas de informação e de comunicação operam no núcleo da subjetividade humana, não apenas no seio das suas memórias, da sua inteligência, mas também da sua sensibilidade, dos seus afetos, dos seus fantasmas inconscientes." (Guattari, 1992, p. 14).

Podemos pensar aqui a noção de formações subjetivas que ressitua o sujeito enquanto 'terminal' de processos que implicam coletividades (humanos e nãohumanos), num cruzamento de múltiplos e heterogêneos componentes. Guattari referese a uma "subjetividade assistida por computador", apontando para o engendramento rizomático inusitado que se pode constituir com as máquinas informacionais.

\section{Conclusões}

A rede, com seus nós de conexões híbridas, potencializa a produção de subjetividades e pode vir a constituir-se, inclusive, enquanto nó para reabilitação psicossocial de portadores de sofrimento psíquico. $\mathrm{Na}$ experiência relatada acima, o trabalho na oficina de informática configura-se como um elemento que faz parte da reabilitação dos usuários do CAPS. Aponta-se a importância da configuração de redes de intervenção que coloquem diferentes agências, tanto acadêmicas quanto de saúde em conexão, pois assim podem se constituir outros sentidos para a vivência da loucura na cidade. As tecnologias enquanto aliadas ao processo podem, a partir de seu uso, ressignificar os lugares de louco enquanto incapaz para a comunidade, família e para os próprios usuários do CAPS.

\section{Referências Bibliográficas:}

CASTELLS, Manuel. A sociedade em rede. A era da informação : economia, sociedade e cultura, v. 1. São Paulo: Paz e Terra, 2000.

BENEVIDES, Regina. Clínica e social: polaridades que se opõem/complementam ou falsa dicotomia?. In: RAUTER, C.; PASSOS, Eduardo; BARROS, Regina de B. (org.). Clínica e Política: subjetividade e violação dos direitos humanos. RJ: Instituto Franco Basaglia/Editora TeCortá, 2002, p. 123 a 140.

COIMBRA, Cecília et. all. Intervenção clínica quanto à violação dos Direitos Humanos: por uma prática desnaturalizadora na teoria, na ética, na política. In: RAUTER, C.; PASSOS, Eduardo; BARROS, R. de B. (org.). Clínica e Política: subjetividade e violação dos direitos humanos. RJ: Instituto Franco Basaglia/Editora TeCortá, 2002, p.113 a 122 .

DELEUZE, Gilles. Conversações. Rio de Janeiro : Ed. 34, 2000.

; GUATTARI, Félix. Mil Platôs : capitalismo e esquizofrenia. Rio de Janeiro : Ed. 34, 1995. 